\title{
ARTICLES
}

\section{EFFICIENT AND STRUCTURED PROGRAMME OF TEACHING FOR METHODS OF FAMILY PLANNING}

\author{
Mrs. Maninder Kaur Brar* | Ms. Seema Raghuvanshi** \\ *Assistant Professor, Department of Nursing, CSHS, Chitkara University, Rajpura, Punjab, India. \\ **Nursing Tutor, Department of Nursing, CSHS, Chitkara University, Rajpura, Punjab, India. \\ DOI: http://doi.org/10.47211/tg.2020.v07i03.006
}

ABSTRACT

\begin{abstract}
Birth prevention includes various Methods and Services given by Government in order to control Pregnancy. Birth prevention approach include self-control, planned parenthood and everything Food. The Researcher selected a sample of 60 female of conceptive age group (18-45 years) using systematic random sampling technique. Analyses of facts and figures were done in accordance with the goals. Method of descriptive and inferential statistics was used, such as mean, percentage, probable error, correlation coefficient and paired t'-test, ANOVA test etc. Pie chart and graphic representations were used to describe the conclusion. Mean knowledge scores of pre-test and post-test for the subjects were used to compare by Paired ' $t$ ' test. ANOVA analyses were used to spot the effect of the selected variables on knowledge, and to find the statistical significance with variables. The Socioeconomic, analytical characteristics of the participant women in relation to determine the efficacy of organized guidance plan of understanding on family planning methods are shown. Structured teaching programme are the best method to impart knowledge.
\end{abstract}

Key Words: Family Planning, Structured teaching Programme.

\section{ABOUT AUTHORS:}

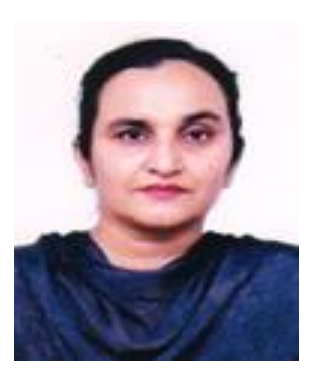

Author Mrs. Maninder Kaur Brar is Assistant Professor, Department of Nursing, CSHS, Chitkara University, Rajpura, Punjab, India.

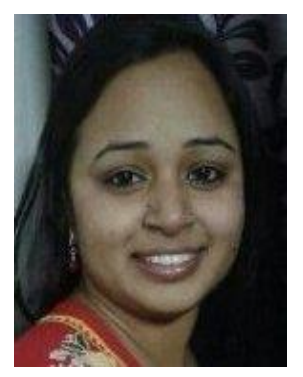

Author Ms. Seema Raghuvanshi is Nursing Tutor, Department of Nursing, CSHS, Chitkara University, Rajpura, Punjab, India. 


\section{INTRODUCTION}

Birth prevention is the self-imposed devising and activity taken by human being to avoid an impregnation. Birth prevention includes various Methods and Services given by Government in order to control Pregnancy. Birth prevention approach include self-control, planned parenthood and everything Food and Drug Administration accepted methods of preventing pregnancy including hormonal barrier method and safety supplies such as sheath, pills and dalkon shield. ${ }^{1}$ Birth prevention benefit include admonish and edification, predisposition guard, covering, experimental analysis and birth prevention systems. Birth prevention is the self-imposed activity and action taken by human beings to anticipate, avoidance or achieve a impregnation, Ripa Ajmera (2010) ${ }^{2}$.According to George Rose $(1998)^{3}$ physical and mental wellness for all is attainment of level of wellness that permits all humans of the world to lead a socially and economically potency existence' Kumar Arjit, Bhardwaj P, Srivastva J P, Gupta P $(2009)^{4}$ the acceptance of birth prevention activities include both transient and durable activities increased with level of education of female Dr. Gaur M.D, Kumar Goel Manish (2010) ${ }^{5}$ the study conducted that the women had very less knowledge about the long acting reversible contraceptive. This study revealed that in Karachi $4.5 \%$ women had heard about the Intra uterine devices (multiload 375 and Copper-T), only 0.5\% women were aware about the long acting reversible contraceptives. This study also conducted that only $20.5 \%$ women had heard about the condom and $0.2 \%$ women had heard about the sub dermal implants and $10.5 \%$ women were aware about the post capital pills and no one having knowledge about vaginal rings.

\section{OBJECTIVES}

1. Evaluation of pre-test knowledge scores for women of reproductive age group (18-45years) regarding family planning methods.

2. Evaluation of post-test knowledge scores for women of reproductive age group (18-45years) regarding family planning methods.

3. Comparison of pre-test and post-test knowledge scores for women of reproductive age group (1845years) regarding family planning methods.

4. To differentiate between knowledge and selected demographical figures such as age in years, living children count, education of woman, education of husband, onset of menarche, parity, woman profession, job of husband, monthly family earnings, place of residence, family type, information source.

\section{MATERIALS \& METHODS}

Quasi experimental access was designed approbate for the current consideration as it is marked to evaluate the capability of programme for Structured Teaching on knowledge of birth control activities among female of conceptive age group (18-45years) in selected village of Moga, Punjab. The Researcher selected a sample of 60 female of conceptive age group (18-45 years) using systematic random sampling technique every $12^{\text {th }}$ female was selected for the study. Reliability of the tool was computed by split half technique \& was calculated by Spearman Brown's Prophecy formula, which was found to be $r=0.8$. The statistical validity of the tool was 0.894 stating it as highly reliable. Analyses of facts and figures were done in accordance with the goals. Method of descriptive and inferential statistics was used, such as mean, percentage, probable error, correlation coefficient and paired $t^{\prime}$-test, ANOVA test etc. Pie chart and graphic representations were used to describe the conclusion. Mean knowledge scores of pre-test and post-test for the subjects were used to compare by Paired ' $t$ ' test. ANOVA analyses were used to spot the effect of the selected variables on knowledge, and to find the statistical significance with variables. 


\section{ARTICLES}

TABLE 1: Socioeconomic / Demographic characteristics of reproductive age group women $(n=60)$

\begin{tabular}{|c|c|c|}
\hline CHARACTERISTICS & Frequency & $(\%)$ \\
\hline \multicolumn{3}{|l|}{ Age (in years) } \\
\hline $18-24$ & 14 & $(23.3)$ \\
\hline $25-31$ & 25 & $(41.7)$ \\
\hline $32-38$ & 17 & $(28.3)$ \\
\hline $39-45$ & 4 & (6.7) \\
\hline \multicolumn{3}{|l|}{ Number of living children } \\
\hline One & 21 & (35) \\
\hline Two & 33 & (55) \\
\hline Three & 6 & (10) \\
\hline More than three & - & - \\
\hline \multicolumn{3}{|l|}{ Education of female } \\
\hline Uneducated & 1 & $(1.7)$ \\
\hline Up to elementary & 27 & (47) \\
\hline Up to middle & 23 & (38.3) \\
\hline Qualify and overhead & 9 & $(15)$ \\
\hline \multicolumn{3}{|l|}{ Education of spouse } \\
\hline Uneducated & 1 & $(1.7)$ \\
\hline Up to elementary & 20 & $(31.6)$ \\
\hline Up to middle & 19 & (31.7) \\
\hline Qualify and overhead & 21 & $(35)$ \\
\hline \multicolumn{3}{|l|}{ Onset of menarche } \\
\hline$\leq 12$ years & 9 & (15) \\
\hline 13 years & 22 & $(36.6)$ \\
\hline 14 years & 16 & $(26.7)$ \\
\hline$\geq 15$ years & 13 & $(21.7)$ \\
\hline \multicolumn{3}{|l|}{ Occupation of women } \\
\hline Housewife & 51 & (85) \\
\hline Government employee & 3 & (5) \\
\hline Private employee & 6 & (10) \\
\hline \multicolumn{3}{|l|}{ Business women } \\
\hline \multicolumn{3}{|l|}{ Occupation of husband } \\
\hline Farmer & 7 & $(11.7)$ \\
\hline Government employee & 19 & (31.7) \\
\hline Private employee & 20 & (33.3) \\
\hline Business man & 14 & $(23.3)$ \\
\hline \multicolumn{3}{|l|}{ Family monthly income } \\
\hline$<5000$ & 12 & (20) \\
\hline $5001-10,000$ & 30 & (50) \\
\hline $10001-15000$ & 15 & (25) \\
\hline$>15000$ & 3 & (5) \\
\hline \multicolumn{3}{|l|}{ Forms of generations } \\
\hline Close generations & 48 & (80) \\
\hline Collective generations & 11 & (18.3) \\
\hline Continued generations & 1 & $(1.7)$ \\
\hline \multicolumn{3}{|l|}{ Source of information } \\
\hline Health professionals & 15 & (25) \\
\hline Mass Media & 18 & (30) \\
\hline Family and Relatives & 13 & $(21.7)$ \\
\hline Neighbours & 14 & $(23.3)$ \\
\hline
\end{tabular}


TABLE-2

Frequency and Percentage distribution of Pre-test and Post-test knowledge score of women of reproductive age group (18-45 years) on Birth Control activities. $(\mathrm{N}=60)$

\begin{tabular}{llcccc}
\hline Conversant Score & & Pre-test & & Post-test \\
\hline $\begin{array}{l}\text { Knowledge } \\
\text { Level }\end{array}$ & Percentage & $\mathbf{n}$ & $\%$ & $\mathbf{n}$ & $\%$ \\
\hline Good & $76-100 \%(23-30)$ & 5 & 8.3 & 55 & 91.7 \\
Average & $51-75 \%(16-22)$ & 47 & 78.3 & 5 & 8.3 \\
Below average & $\leq 50 \%(\leq 15)$ & 8 & 13.3 & 0 & 0 \\
\hline
\end{tabular}

TABLE-3

Correlation of Mean Pre-test and Post-test Knowledge women score about family planning methods. $\mathbf{N}=60$

\begin{tabular}{cccccccc}
\hline \multicolumn{7}{c}{ Conversant Score } \\
\hline & $\mathbf{n}$ & Mean & SD & Mean & SD & df & ' $\mathbf{t}$ ' \\
\hline \multirow{2}{*}{ Conversant Score } & 60 & 18.58 & 2.664 & 25.22 & 1.563 & 59 & 17.375 \\
\hline
\end{tabular}

\section{RESULTS}

The Socioeconomic, analytical characteristics of the participant women in relation to determine the efficacy of organized guidance plan of understanding on family planning methods are shown in Table- 1 . The highest numbers of females were in the age group of $25-31$ years (41.7\%) and lowest numbers of females were in age group $39-$ 45 years $(6.7 \%)$. The maximum numbers of children were two $(55 \%)$ and minimum numbers of children were three (10\%). The maximum number of women were up to Primary $(47 \%)$ and minimum number of women were illiterate $(1.7 \%)$. The maximum numbers of husband were educated up to graduation (35\%), and minimum were illiterate (1.7\%). The maximum number of women were having onset of menarche at the age of 13 years (36.6\%) and minimum number of women were having onset of menarche at age of $\leq 12$ years (15\%). The maximum numbers of women were housewives (85\%) and minimum number of women were doing government job (5\%). The maximum number of husbands were businessman (23.3\%) and minimum number of husbands were belonging to government job (31.7\%). The maximum number of women belongs to income group $5001-10,000$ (50\%) and minimum number of women belongs to income group $\geq 15000$ (5\%). The maximum number of women were belonging to nuclear family (80\%) and minimum number of women were belonged to extended family (1.7\%). The maximum figure of female acquires details from mass media (30\%), minimum figure of female acquires details from family or relatives (21.7). Table 2: reveals that, in pre-test, majority of women (78.3\%) had average knowledge, $13.3 \%$ of them had below average knowledge and $8.3 \%$ of them had good knowledge. In Post-test, maximum number of women (91.7\%) possesses quality comprehension score and $8.3 \%$ of them had average knowledge score on family planning methods. Table 3: manifest that knowledge score for the mean pre-test was (18.58) and knowledge score for post-test was (25.22).

\section{DISCUSSION}

Analysis of the pre-test and post-test knowledge score reveal that the higher post-test mean knowledge score among women of reproductive age group (18-45 years) on family planning methods. In present study maximum numbers of women (41.7\%) were in age group 25-31 years in group, maximum numbers of women (55.0\%) were having two children, maximum numbers of women (47\%) were educated up to primary, maximum numbers of husband (35\%) were educated up to graduation, maximum numbers of women (36.6\%) were having onset of menarche at the age of 13 years, maximum numbers of women (85\%) were housewives, maximum numbers of husband (33.3\%) were businessman, maximum numbers of women (50\%) were belonged to income group 5001$10,000$, highest figures of females ( $80 \%)$ belonged into nuclear family, maximum numbers of women $(30 \%)$ got information from mass media.

\section{CONCLUSION:}

Structured teaching programme are the best method to impart knowledge. 


\section{ARTICLES}

\section{REFERENCES}

1. King Abdullah. Natural Family Planning. Arabic Health Encyclopaedia. January 2013.

2. Ajmera Ripa. What is the importance of family planning? Live Strong.com. January 10, 2010.

3. Dhar Aarti. More couples adopting family planning measures. Current statistics. The Hindu. NEW DELHI. 2010-2011.

4. Kumar Arjit, Bhardwaj, Gupta Srivastva. Text book of Preventive and Social Medicine. $18^{\text {th }}$ edition. Bhanot publishers; (2009).

5. Dr. Gaur MD. Text book of methods of family planning. $3^{\text {rd }}$ edition. Pp 225-230.2010. 